aqua regia is used, or if lead is present, sulphuric acid is added and evaporation continued until the heavy white fumes of sulphuric anhydride are evolved. The excess of sulphuric acid is neutralized with ammonia and three cc. of concentrated nitric acid added.

Providing sulphuric acid is not added it is only - necessary to concentrate to three cubic centimeters. In either case the solution is diluted to $75 \mathrm{cc}$, transferred to a tall battery beaker, without being filtered (if the residue does not settle it is better to filter) and the copper deposited by means of a current of 8 to Io amperes and 3 to 4 volts. If the deposit is black or dark colored it is dissolved in nitric acid and redeposited in the same way. This redeposition is, as a rule, easier and quicker than filtering. The following results show the accuracy of this method on ores, as compared with those obtained by the older method.

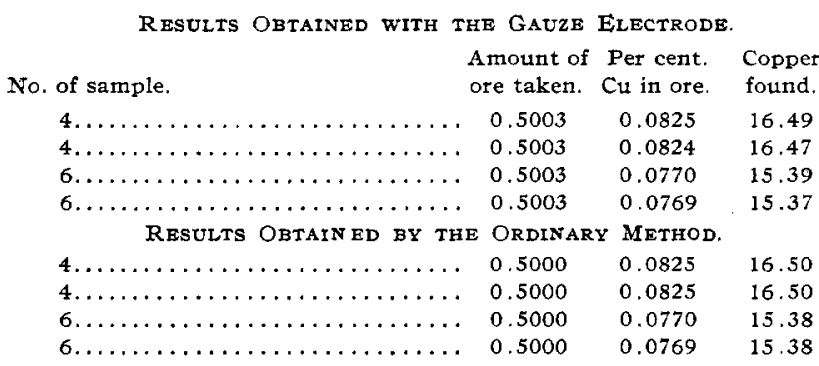

Process for Slags. - In case of slags and other low-grade material it is necessary to select a method of disintegration suited to the particular material in hand. Slags, which always give large quantities of gelatinous silica and contain low percentages of copper, give the most accurate results when disintegrated by means of nitric acid followed by hydrofluoric and sulphuric acids. After evaporation until heavy white fumes are evolved, the analysis is finished as in the process with ores. Redeposition is more frequently necessary with low-grade material than with high-, but in all cases it is more rapid, as well as more accurate, than filtering.

The following will illustrate the accuracy of the procedure:

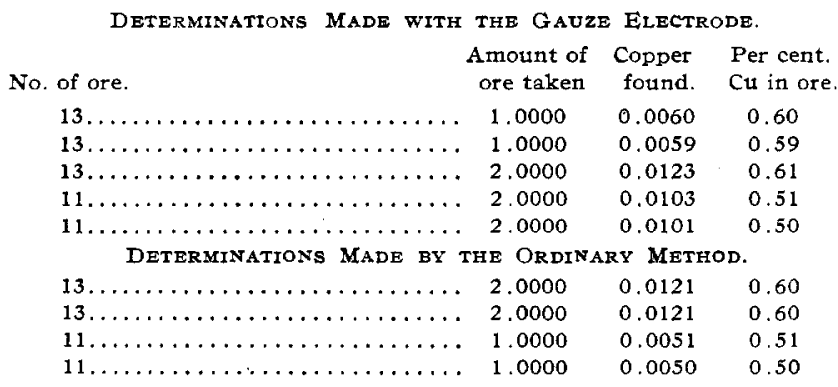

Elements which interfere, and at the same time are likely to occur in copper ores, are arsenic, antimony, lead and bismuth. The separation of antimony and bismuth from copper was tried under the preceding conditions but without success. Lead, in such quan- tities that it will deposit with the copper, is best removed as the sulphate. Arsenic, in small quantities, will not deposit with the copper, but in amounts about equivalent to the copper present begins to be deposited with the last of this. The following series of experiments, in which copper was deposited in the presence of varying amounts of arsenic, illustrates this point.

Arsenic taken.
0.0605
0.1210
0.1815
0.1210
0.2420

Copper taken.
0.2652
0.2751
0.2183
0.3038
0.2686
0.2028

Copper found.
0.2648
0.2747
0.2183
0.3035
0.3106
0.2026

All these depositions were made under the usual conditions. From these results it is seen that arsenic, when present in amounts large enough to contaminate the copper deposited, can easily be removed by dissolving the deposited copper and reprecipitating under the same conditions as, before. The removal of the interfering elements by chemical means can be accomplished by the following method:

The ore is disintegrated with nitric and hydrochloric acids, five or six cubic centimeters of sulphuric acid added and then it is evaporated until heavy white fumes of sulphuric anhydride are given off. It is now diluted to one hundred and fifty cubic centimeters with water, boiling to insure complete solution of the basic sulphate of iron (a few drops of hydrochloric acid are added if silver is present), filtered and washed with water containing a little sulphuric acid. The lead and silver remain on the filter paper. The filtrate is now heated to boiling and saturated with hydrogen sulphide, allowing the solution to cool during the process. The precipitated copper sulphide is filtered off and washed with water containing hydrogen sulphide. The precipitated sulphides are rinsed from the filter paper into a beaker using as little water as possible, warmed with a little colorless sodium sulphide to remove the antimony and arsenic and again passed through the same filter, being washed with water containing some sodium sulphide. Bismuth is now removed from copper by warming the mixed sulphides with a solution of potassium cyanide alkaline with ammonia. This dissolves the sulphide of copper leaving that of bismuth insoluble. The solution of the copper is boiled with nitric acid to destroy the potassium cyanide and electrolyzed in the usual manner.

UNIV. OF ARIZONA, TUCSON.

\section{THE EXACT DETERMINATION OF SULPHUR IN PYRITE AND MARCASITE.}

By E. T. ALLEN AND JOHN Johnston. Received March 8, 1910.

Technical chemists have regarded the determination of sulphur in pyrite, which serves as the starting point in the manufacture of vast quantities of sul- 
phuric acid, of very high importance. The fact is abundantly attested by the great body of literature which has been devoted to the subject. This has been well summarized by Lunge, who has himself made valuable contributions to it. ${ }^{1}$ Lunge's well-known method, as formerly carried out, with a slow precipitation of the barium sulphate, gave results which were considerably too low. As since modified by the rapid precipitation suggested by Hintz and Weber, ${ }^{2}$ it is more accurate, but, as we have elsewhere shown, ${ }^{3}$ the results of the improved method involve a number of variable errors which compensate one another only partially. In the method which we have to propose, the results obtained under carefully regulated conditions are corrected for actual errors by methods which have been fully studied, and though it is less convenient in some respects than Idunge's method and lays no claim to rapidity, it should be of value as an umpire method.

Although the errors in the determination of pyrite and marcasite are chiefly the errors involved in the precipitation of barium sulphate from a solution of sodium sulphate and sodium chloride, very considerable errors may be involved in the grinding of the material.

Oxidation of the Sulphides of Iron in Dry Grinding.It is well known that the sulphides of iron, especially marcasite, gradually oxidize when exposed to the atmosphere. We have frequently noticed a strong odor of sulphur dioxide on opening a bottle containing any of them, more particularly when finely ground. During the operation of grinding, oxidation appears to be accelerated, probably by the local heating in the disruption of particles. ${ }^{4}$ The evolution of sulphur dioxide is not sufficiently rapid to be noticed in the grinding but, as shown below, ferrous sulphate is always found in the ground material. The data follow:

Pyrite.-A sample of pure pyrite from Elba was ground for an hour in the agate mortar of a McKenna ore-grinder. The product was washed on a filter paper and the iron and sulphur were determined in the soluble portion.

$$
\begin{array}{r}
\mathrm{Fe}=0.0117 \mathrm{~g}^{\mathrm{s}} \text { equiv. to } 50,0.0200 \mathrm{~g} . \\
\text { SO, found } 0.0202 \mathrm{~g} .
\end{array}
$$

A Another portion of the same sample, ground 6 hours, yielded a water extract which contained:

$$
\mathrm{Fe}=0.0253 \text { g. equiv. to } \mathrm{SO}_{4} 0.0434 \mathrm{~g} \text {. }
$$

$\mathrm{SO}_{4}$ found $0.0435 \mathrm{~g}$.

Marcasite.-A sample of marcasite from Joplin, Mo., also ground six hours and extracted with water, gave:

1 Report Int. Com. on Analysis, Subcommittee 9, 5th Int. Cong. Applied Chemistry, Rome, 1906, p. 399.

${ }^{2} Z$, anal. Chem., 45, 31 (1906).

${ }^{3} J$. Am. Chem. Soc., 32, 602.

4 The ferrous silicates behave in a similar way. See Mauzelius, Arsbok Sveriges Geologiska Undersökning, 1907, No. 3. Hillebrand, J. Am. Chem. Soc., 30, 1120 (1908).

$B$ On the assumption that the soluble iron exists wholly as ferrous sulphate.

$$
\mathrm{Fe}=0.0079 \mathrm{~g} . \text { equiv. to } \mathrm{SO}_{4} 0.0136 \mathrm{~g} .
$$

Pyrrhotite.-A sample of artificial pyrrhotite containing only a little sulphur in excess of the ratio $\mathrm{Fe}: \mathrm{S}=\mathrm{I}: \mathrm{I}$, gave on the same treatment:

$$
\mathrm{Fe}=0.0057 \mathrm{~g} \text {. equiv, to } \mathrm{SO}_{4} 0.0098 \mathrm{~g} \text {. }
$$$$
\mathrm{SO}_{4} \text { found } 0.0092 \mathrm{~g}
$$

These figures show plainly that ferrous sulphate is formed in grinding the sulphides of iron. The ground material yielded no oxide of iron when digested with 20 per cent. hydrochloric acid (conc. $\mathrm{HCl}$ diluted with an equal volume of water); ferrous sulphate and sulphur dioxide are therefore the only products of oxidation and the reaction may be represented by the equation

$$
\mathrm{FeS}_{2}+{ }_{3} \mathrm{O}_{2}=\mathrm{FeSO}_{4}+\mathrm{SO}_{2}
$$

The weights of sulphide taken are not included in the above data, because it was found that a part of the oxidation in these experiments occurred during the washing. To eliminate this error, in the following experiments the ground material was washed in an atmosphere of carbon dioxide. The apparatus, enclosing a funnel with dry filter to which the ground material was transferred, was first exhausted by an ordinary water pump, and filled with carbon dioxide which had been freed from oxygen by heated copper.

\begin{tabular}{|c|c|c|c|}
\hline & SIDATION & IG PYRITE. & \\
\hline $\begin{array}{l}\text { Taken. } \\
\text { Gram. }\end{array}$ & $\begin{array}{l}\text { Fe in } \\
\text { filtrate. } \\
\text { Gram. }\end{array}$ & $\begin{array}{c}\text { Equiv. to } \\
\text { FeS2. } \\
\text { Gram. }\end{array}$ & $\begin{array}{c}\text { Per cent } \\
\text { FeS } \\
\text { oxidized. }\end{array}$ \\
\hline 4.11 & 0.0042 & 0.0090 & 0.22 \\
\hline 5.77 & 0.0059 & 0.0126 & 0.22 \\
\hline & & & \\
\hline 4.21 & 0.0211 & 0.0451 & 1.07 \\
\hline 6.13 & 0.0317 & 0.0679 & 1.11 \\
\hline
\end{tabular}
To remove oxygen more completely from the apparatus the process of exhaustion and filling with carbon dioxide was repeated. The sulphide was now washed with boiled water which had been cooled in carbon dioxide.

A mixture of 99 pts. $\mathrm{FeS}_{2}$ plus $\mathrm{I} .3$ pts. $\mathrm{FeSO}_{4}$ would be formed by the oxidation of I per cent. of the pyrite. Such a mixture contains only 53.02 per cent. instead of 53.45 per cent. sulphur. Thus when I per cent. of the pyrite is oxidized, the sulphur found in analysis should be 0.43 per cent. too low. This corresponds to a loss of $0.43 / 0.53=0.8$ per cent. of the sulphur originally present. A six-hour grinding may perhaps be regarded as excessive, but it is probable that the time is not so important as the degree of fineness to which the material is reduced. The operation is manifestly one which is likely to vary considerably, differences of pressure on the pestle especially influencing the rate of oxidation. The above figures are not intended as an accurate measure of this rate, but are quoted merely to show that grinding causes oxidation, the errors from which must be considered 
in exact work, especially when, as Treadwell directs, the material is ground as fine as possible. ${ }^{1}$

As a matter of fact fine grinding is not necessary in the method given below, except as it enables one to mix inhomogeneous material thoroughly. If the material is not sufficiently homogeneous, the extent of oxidation in the finely-ground sample should be determined in the way just indicated. As far as the analysis is concerned, one can use, perfectly well, material which will pass through a 20-mesh screen. When the sulphides are gently crushed to this size there is scarcely any oxidation as the following experiments serve to prove.

Perfectly bright pyrite from the interior of a solid lump, and therefore presumably free from oxidation, was gently crushed in a hard steel mortar and passed through a 20-mesh screen. $3.75 \mathrm{~g}$. of the screenings were treated with boiled water in an atmosphere of carbon dioxide as above.

Fe in the filtrate $=0.0009 \mathrm{~g}$, equiv. to $0.0019 \mathrm{~g}$. FeS $\mathrm{S}_{2}$ or $0.05 \%$ oxidized.

In a duplicate experiment, $4.6 \mathrm{I} \mathrm{g}$. gave:

$\mathrm{Fe}$ in the filtrate $=0.0010 \mathrm{~g}$. equiv, to $0.0021 \mathrm{~g}$. FeS $2=0.05 \%$ oxidized.

Preparation of Material for Analysis.-The samples of the minerals which were used in the subsequent analyses were as pure as could be found. The marcasite was from Joplin, Mo., and the pyrite from Elba. They were further purified from oxidation products in order to obtain uniform samples, as well as to increase the certainty of the analytical determinations. It will of course be understood that such a procedure is not applicable to commercial work. To remove the oxidation products both samples were boiled with 20 per cent. hydrochloric acid until fresh portions of the reagent were no longer colored. They were then washed very carefully in an atmosphere of carbon dioxide. The washing was done first with 20 per cent. hydrochloric acid, then with boiled water cooled in carbon dioxide. The filters and their contents were now transferred to vacuum desiccators which had previously been filled with carbon dioxide. The desiccators were then rapidly exhausted, first by the water pump, then by the mercury pump to a pressure of I $\mathrm{mm}$. of mercury or less. These samples were not absolutely homogeneous; each contained a little quartz, but so little that it was believed that any error occasioned by the lack of uniformity was less than the errors of analysis. The samples thus. prepared were used for all the subsequent work. They were kept in vacuum desiccators and only exposed to the air long enough to take out portions for analysis.

Determination of the Sulphur. a. Oxidation.-To insure the complete oxidation of the sulphur with absolutely no loss, we employed the method of Carius. About 4 cc. fuming nitric acid entirely free from sulphur were used for the oxidation of half a gram of

\footnotetext{
1 "Quant. Anal.," trans. by Hall, p. 281.
}

sulphide. The sealed tube, containing the sulphide and reagent prepared in the ordinary way, was heated to $125^{\circ}$ (maximum) over night. ${ }^{1}$ The excess of nitric acid was removed after transferring to a beaker by evaporation to dryness on the steam-bath, the operation being several times repeated with concentrated hydrochloric acid. The beaker was covered with a watch glass so long as there was any danger of loss from spattering.

b. Separation of the Iron.-The sulphate of iron was cooled and brought into solution with water (no acid is necessary), diluted to about $300 \mathrm{cc}$. and precipitated with sodium carbonate solution ( 5 per cent. solution of $\mathrm{Na}_{2} \mathrm{CO}_{3}$ is suitable) with constant stirring. Only a slight excess should be used. The addition of a few drops of ammonia makes the precipitation complete. The precipitate settles well after warming on the steam-bath. Sodium carbonate was used instead of ammonia, because, as will be explained farther on, the losses of sulphur are much increased when barium stulphate is precipitated from ammonium sulphate. The precipitate of ferric hydroxide was now filtered and washed; to insure the complete separation of sulphur it was redissolved in the least possible quantity of 20 per cent. hydrochloric acid, and the iron reprecipitated. The second filtrate and washings were kept separate from the first.

c. Precipitation of the Sodium Sulphate by Barium Chloride.-Each of the above filtrates was now brought to a volume of about $350 \mathrm{cc}$, either by dilution or evaporation as the case may require. The solutions were just acidified by hydrochloric acid, with the aid of a drop or two of methyl orange, then 2 cc. 2 per cent. hydrochloric acid ( $\mathrm{I}$ vol. conc. $\mathrm{HCl}$ diluted to 20 vol.) were added to each. In the precipitation of the barium sulphate, as will be explained farther on, the rate at which the reagent $\left(22.5 \mathrm{cc}\right.$. in quantity) ${ }^{2}$ is added is all important. This is best regulated by attaching a capillary tip to the burette. The right diameter may be found by a few trials. The sulphate solutions were heated boiling hot and vigorously stirred while the reagent was allowed to flow down the side of the beaker. The precipitates were then left $\mathrm{t}^{3}$ to stand for about I8 hours, when thcy were filtered on paper and washed with hot water, till $25 \mathrm{cc}$. washings showed only the faintest opalescence with silver nitrate. Filtering and washing thus requires usually $I-I \frac{1}{4}$ hours. The wet paper and precipitate were then heated very slowly and carefully in a platinum crucible, and finally, when the combustion was complete, ignited to constant weight.

1 The glass tubes were heated in long steel bombs containing water. which served to compensate the pressure inside. This apparatus was at hand for other work and was used as a matter of convenience, but it was doubtless unnecessary.

$20.5 \mathrm{~g}$. pure $\mathrm{FeS}_{2}$ requires about $21 \mathrm{cc}$ of 10 per cent. $\mathrm{BaCl}_{2}$ solution. i. e., $10 \mathrm{~g}$. $\mathrm{BaCl}_{2} 2 \mathrm{H}_{2} \mathrm{O}$ in $100 \mathrm{cc}$. $\mathrm{H}_{2} \mathrm{O}$.

${ }^{3}$ A Gooch crucible may be used, but precipitates formed in solutions containing very little acid are voluminous and inclined to clog the asbestos Gilter. 
d. Errors in the Determination of Sulphur and their Corrections. ${ }^{1-W h e n}$ a precipitation of barium sulphate is thus made from a solution of sodium sulphate, the weight of the precipitate is always too low. The authors have made a detailed study of the errors in the above case and of the methods of correcting them; these will here be briefly summarized:

I. The removal of nitrates is necessary, as has long been recognized; barium sulphate carries down nitrates and consequently the results are too high.

2. The solubility of the barium sulphate, of course, occasions a small loss, which is, however, much increased by free acid. With the quantity recommended, 2 cc. 2 per cent. $\mathrm{HCl}$ in a volume of $350 \mathrm{cc}$., and an added volume of $350 \mathrm{cc}$. washings, it amounts to $\mathrm{I}-2 \mathrm{mg}$. only. It is not increased by the presence of sodium chloride. The solubility is determined in the usual way by evaporation of the filtrate and washings to dryness in a platinum basin, taking up with a little water and washing on a small filter, burning and weighing the precipitate.

3. All barium sulphate precipitates which have formed from alkali sulphates contain a number of impurities: barium chloride, alkali sulphate and "free" sulphuric acid, probably in the form of acid sulphate of the alkali metal. The quantity of alkali sulphate carried down by barium sulphate depends on many conditions, the most important of which are the quantities of free acid and alkali chloride present in the original solution. Barium sulphate from pure sodium sulphate carries down about 0.5 per cent. of the latter. This is more than doubled in the presence of much sodium chloride. The quantity may be determined by dissolving the weighed precipitate in $15 \mathrm{cc}$. concentrated sulphuric acid and pouring the cooled solution into about $300 \mathrm{cc}$. water with constant stirring. The precipitate and solution are heated some time and then filtered. The filtrate is carried to dryness in platinum under a hood with good draft and finally heated to redness. The residue is dissolved in a little water, filtered into a small tared dish, evaporated again to dryness, heated to redness, and weighed. This process does not extract all the sodium sulphate. Experiment has shown that the addition of Io par cent. more to the quantity thus extracted will give the total amount with sufficient accuracy. If the analysis is made according to the directions in this paper, the quantity of sodium sulphate obtained by a single extraction in the precipitate should be close to $8.3 \mathrm{mgs}$. and the correction for it found by multiplying this quantity plus io per cent. by the factor $\left(\mathrm{BaSO}_{4}-\mathrm{Na}_{2} \mathrm{SO}_{4}\right) / \mathrm{Na}_{2} \mathrm{SO}_{4}, 5.8 \mathrm{mgs}$. If the iron is precipitated by ammonia the solution will, of course, contain ammonium sulphate and the barium sulphate precipitated from it will contain a considerable quantity of ammonium sulphate, which volatil-

\footnotetext{
${ }^{1}$ For a full discussion of this subject, see f. Am. Chem. Soc., 32, 604-6.
}

izes when the barium sulphate is heated, thereby occasioning a loss considerably larger than that caused by the non-volatile sodium sulphate. Naturally, if corrections are to be made, they should, in the interests of accuracy, be kept as low as possible.

4. The Loss of Sulphuric Acid by Volatilization.-Barium sulphate which has been precipitated from solutions of any of the alkali sulphates contains some "free" sulphuric acid, or presumably, acid sulphate of the alkali metal. This acid is lost on heating, though the precipitate remains quite neutral. This remarkable fact has been fully substantiated by many experiments. The losses are much increased by two conditions-the presence of free acid and of alkali chloride, and will easily surpass one per cent. of the total sulphur if the quantity of both these substances is not carefully limited. There is another condition also that exercises an important fuence on it, viz., the speed of precipitation. If this be rapid (ca. Io secs.), the quantity of "free" sulphuric acid is lowered and under certain conditions practically vanishes. The determination of the volatility loss is best made by heating in a platinum boat, inside a platinum combustion tube, a precipitate formed under the same conditions as the one which is weighed. With the outlet of the combustion tube is connected a Liebig potash bulb containing ro $\mathrm{cc}$. water and I cc. perhydrol free from sulphur. When the loss is comparatively large, two bulbs are needed and the quantity of perhydrol is increased. As a precaution it is well to rinse the combustion tube with water after the experiment. With the conditions recommended, the error from this cause is only $0.6 \mathrm{mg}$. for $2 \mathrm{~g}$. precipitate, corresponding to 0.03 per cent. of the total sulphur.

5. The Occlusion of Barium Chloride.-All freshly precipitated barium sulphate contains some barium chloride. This amounts to only about 0.15 per cent. in precipitates which are slowly formed in sodium stulphate solutions; it introduces no error in the determination, because the chloride is transformed by the occluded sodium sulphate during ignition into barium sulphate and hydrochloric acid, and all but a trace of the chloride is thus eliminated. If the precipitation is rapidly made, the amount of chloride in the precipitate is much greater and several tenths of a per cent. remain in the precipitate after heating to redness. Thus another correction is necessitated.

6. Effect of the Time of Standing on the Composition of Barium Sulphate Precipitates.-When precipitates are left to stand in the liquid from which they are thrown down, they slowly change in composition, approaching somewhat nearer to pure barium sulphate. The process is accelerated to some extent by heating, though the addition of a large excess of barium chloride has no effect. In exact determinations of sulphur, therefore the barium sulphate should not be filtered 
at once for in that case the losses from both occlusion and volatilization are higher. I8 hours is a practical time to allow before filtering. The corrections given in this paper imply this condition. The authors have found that the corrections discussed in the preceding paragraphs are quite constant when the prescribed conditions are strictly adhered to. In the analyses which follow, the results have therefore been corrected by the use of constants previously determined under similar conditions.

One analysis each of pyrite and marcasite was made exactly according to the method described above; two others were made by a slightly modified method in which magnesium oxide ${ }^{1}$ was used to precipitate the iron. This method has the advantage that the results obtained by it, require only a solubility correction, for magnesium sulphate is carried down by barium sulphate in almost negligible quantity. This error, which lowers the result slightly, is practically compensated by the presence in the precipitate of a little barium chloride (O.IO-O.I5 per cent.). The volatility loss is a mere trace. The method has the disadvantage that the precipitated iron (or probably the excess of magnesium oxide in it) retains sulphur persistently. Three precipitations were in fact required to recover all the sulphur.

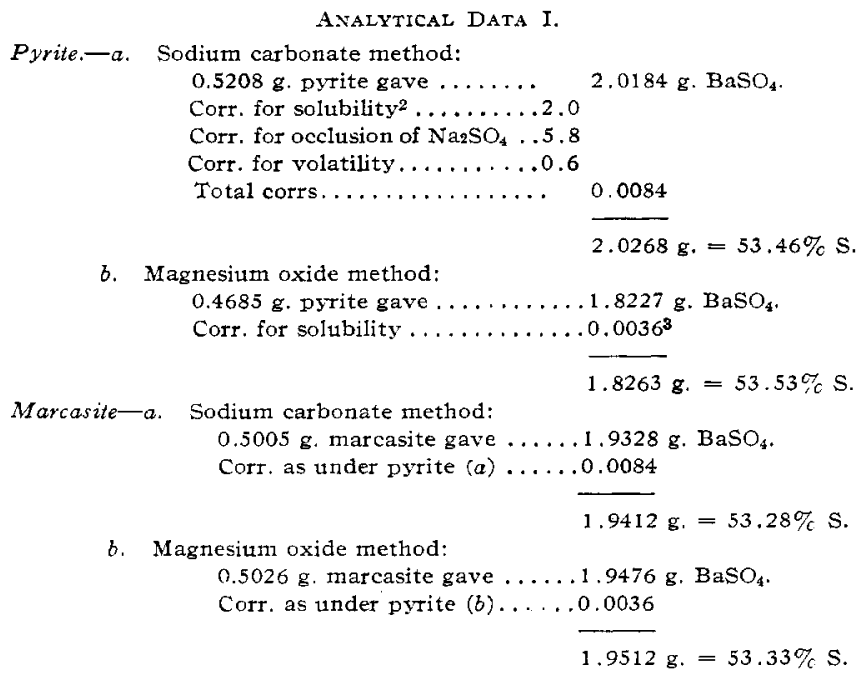

A few determinations for the sake of comparison have been made by Fresenius' and by Lunge's method both somewhat modified. The results have also been corrected for the errors already discussed. Even after correction, however, we do not regard the results on coarse material as equal in accuracy to those just given.

Corrected Analyses by Fresenius' Method.-It is

1 The reagent was carefully freed from lime and sulphur.

2 The correction for solubility is $1 \mathrm{mg}$. for each of the two solutions. Both were brought to a volume of $350 \mathrm{cc}$. so that the same correction might be used for both.

3 The correction obtained experimentally is multiplied by 3 because three precipitations, and therefore three solubility corrections, were necessary. commonly directed in this method to pulverize the sulphide before fusing with sodium carbonate. But since we have shown that this operation may involve a considerable error, the following analyses were made on the 20-mesh material. Only in details was there any change in the ordinary procedure. For the sake of certainty in correction, we fused with a mixture of 4 pts. sodium carbonate and I pt. sodium nitrate (instead of nitre). ${ }^{1}$ Six grams of the mixture were used. The fusion was heated in a platinum crucible, first over a burner and finally for a few minutes over the blast; meanwhile, it was protected from the sulphur of the flame by a good-fitting asbestos board. The cooled fusion was extracted with water and the precipitate well washed. The iron was redissolved and reprecipitated as described under the first method. Both filtrates were brought to about $350 \mathrm{cc}$. and acidified as there described; the remainder of the procedure is also the same in every way. In correcting the weight of the precipitate it must be remembered that the sulphate was precipitated from a solution containing close to $6 \mathrm{~g}$. of sodium chloride, the amount yielded by $6 \mathrm{~g}$. of the above fusion mixture. The presence of this salt makes a considerable difference in the composition of the precipitated barium sulphate and therefore in the corrections to be applied to it. The occluded sodium sulphate amounts on the average to $17.4 \mathrm{mg}$. (for $2 \mathrm{~g}$. precipitate) and the correction for it (after an allowance of Io per cent. for incomplete extraction) I $2.2 \mathrm{mg}$; t the average volatility loss is $5.9 \mathrm{mg}$., while the solubility loss remains unchanged, $2.0 \mathrm{mg}$. The sum of these corrections is $20.1 \mathrm{mg}^{2}$

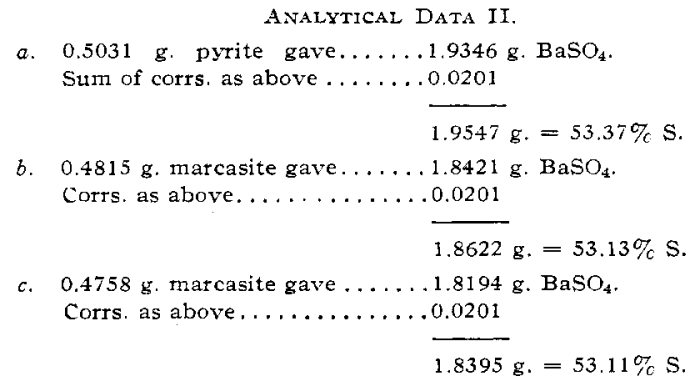

Corrected Results by Lunge's Method.-The weighed quantity of sulphide crushed to 20-mesh size was allowed to stand over night in the cold with ro cc. of a mixture of 3 vol. conc. nitric acid and I vol. conc. hydrochloric acid. The solution was then evaporated on the steam bath, first without, then several times with hydrochloric acid to remove the nitric acid. The remainder of the analysis was exactly like the method proposed and described above.

\footnotetext{
I The correction constants were determined on precipitates of barium sulphate which were thrown down in solutions containing cnly scdium salts.

2 The correction constants were determined on precipitates formed in the presence of $5 \mathrm{~g}$. and $10 \mathrm{~g}$. NaCl respectively. The occlusion number is practicaliy identical for both. The volatility losses are $5.2 \mathrm{mg}$. and 8.8 mg. respectively; by interpolation we obtain $5.9 \mathrm{mg}$. for $6 \mathrm{~g}$. NaCl
} 
Analytical Data III.

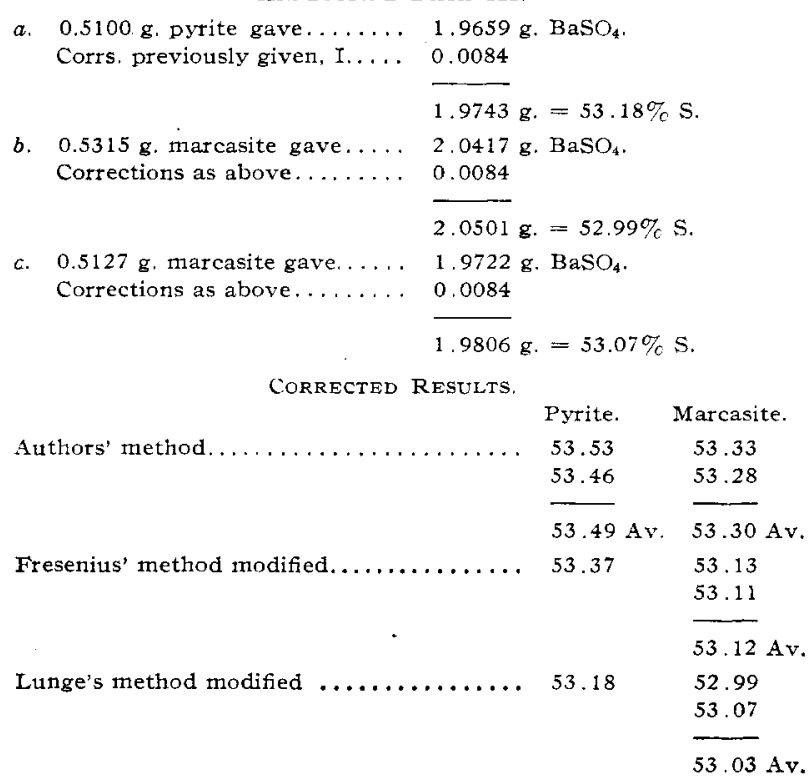

The concordance in the duplicates given above shows that the determinations were carefully done. We ascribe the lower results by Fresenius' ${ }^{1}$ and Lunge's methods to a loss of sulphur during oxidation. In the last determination of the sulphur in marcasite, a little unoxidized sulphur was in fact noticed. The loss probably would not have occurred had the material been finely ground, but if fine grinding is resorted to another error is introduced. The Carius method of oxidation avoids both errors.

Control of Sulphur Determinations.-For the sake of control, 5-g. portions of both pyrite and marcasite were subjected to qualitative analysis. Except for a trace of copper in the marcasite only silica was found: 0.04 per cent. in the pyrite, and 0.20 per cent. in the marcasite. As a final check on the accuracy of the sulphur determination, it seemed desirable to determine also the amount of iron in portions of the same purified pyrite and marcasite.

\section{DETERMINATION OF THE IRON.}

I. Volumetric.-About $0.25 \mathrm{~g}$. substance was decomposed in the usual way with ro cc. of a mixture of 3 parts conc. $\mathrm{HNO}_{3}$ to I part conc. $\mathrm{HCl}$. The excess of acid was gotten rid of by evaporating with sulphuric acid, first on the water bath and finally over a free flame, until voluminous white fumes appeared. The residue was dissolved and diluted with water to about $200 \mathrm{cc}$, nearly neutralized with ammonia, ${ }^{2}$ reduced with sulphur dioxide, ${ }^{3}$ and titrated as usual with permanganate solution, in the presence

1 The possibility that a loss of $\mathrm{SO}_{3}$ may be caused by the contamina. tion of the precipitate by iron should also be considered. In Fresenius method, a little iron is dissolved when the fused mass is leached by water. This iron would probably be carried down by the barium stulphate as ferric sulphate, which would lose sulphur on ignition. See Jannasch and Richards J. pr. Chem., 39, 321; E. A. Schneider, Z. physik. Chem., 10, 425, 1892.

2 In presence of much free acid the reduction is incomplete. Private communication from W. F. Hillebrand and R. S. McBride.

${ }^{3}$ In every case complete reduction was assured by testing a drop of the liquid with thiocyanate. of sufficient added sulphuric acid. A weight burette was used throughout. The permanganate solution was standardized by means of sodium oxalate ("nach Sörensen," obtained from Merck), which had been previously heated for an hour at $240^{\circ} .^{1}$ As a result of several closely agreeing determinations, I g. $\mathrm{KMnO}_{4}$ solution $=0.002633$ g. Fe. A number of blank experiments were performed, and the amount of permanganate used up in them, varying from 0.05 to $0.07 \mathrm{~g}$., was subtracted from the quantity used in titration. The amounts given below have been corrected in this way.

(a) $0.2682 \mathrm{~g}$. pyrite required (1) $47.62 \mathrm{~g}$. , (2) $47.54 \mathrm{~g}$. permanganate.

(b) $0.2682 \mathrm{~g}$. pyrite required (1) $47.53 \mathrm{~g}$., (2) $47.63 \mathrm{~g}$. permanganate.

The percentage of iron from these four analyses is therefore: $46.75,46.67,46.66$ and 46.75 ; the mean value is 46.72 per cent. $\mathrm{Fe}$, whereas $\mathrm{FeS}_{2}$ requires 46.55 per cent. Fe.

(a) $0.2576 \mathrm{~g}$. marcasite required $45.62 \mathrm{~g}$. permanganate.

(b) $0.2719 \mathrm{~g}$. marcasite required (1) $48.01 \mathrm{~g}$. (2) $48.06 \mathrm{~g}$. permanganate

The percentage of iron from these three analyses is $46.63,46.49$ and 46.54 ; the mean value is 46.55 per cent. Fe.

2. Gravimetric.-The first determinations of the iron were made by the gravimetric method. To our surprise, they were all unaccountably high. As a result of some study it may be said that determinations by this method are invariably too high if certain precautions are not taken, and in view of the importance of the method our experience is here included.

If the precipitation is done in platinum by pure ammonia, the results leave little to be desired. In the following determinations, the sulphide was dissolved in aqua regia, the excess of acid removed by evaporation, the residue dissolved and filtered into platinum and twice precipitated by pure ammonia. In this precipitation the details given by Lunge were followed, viz., the liquid was heated to a temperature of $40-50^{\circ}$, the ammonia added and the whole then heated to boiling. In the second precipitation macerated filter paper was added to the solution to make the ignited precipitate more porous and to insure the complete reoxidation of any magnetite formed in the burning. ${ }^{2}$ The second precipitate was thoroughly washed by the aid of the pump. The ammonia used was purified by distillation, the washed vapors being absorbed by water in a ceresin bottle; $25 \mathrm{cc}$. of this ammonia gave no weighable residue.

Pyrite (a) 0.5272 g. gave 0.3504 g. $\mathrm{Fe}_{2} \mathrm{O}_{3} ; \mathrm{Fe}=46.46 \%$.
(b) 0.5344 g. gave 0.3557 g. $\mathrm{Fe}_{2} \mathrm{O}_{3} ; \mathrm{Fe}=46.53 \%$.

The mean value, 46.49 , agrees very closely with the theoretical number for $\mathrm{FeS}_{2}$, viz., 46.55 per cent. $\mathrm{Fe}$.

1 This heated salt (as was afterwards observed) reacted very slightly alkaline, due to the formation of a trace of sodium carbonate, but cannot account for the fact that the volumetric results are somewhat higher than the final results obtained by precipitation with ammonia. Any other impurity in the oxalate, if neutral to permanganate, would of course make the percentage of iron too high.

2 W. F. Hillebrand, Bull. U. S. G. S. 305, D. 88 
Marcasite (a) 0.5028 g. gave 0.3344 g. $\mathrm{Fe}_{2} \mathrm{O}_{2} ; \mathrm{Fe}=46.49 \%$ (b) $0.5209 \mathrm{~g}$. gave $0.3471 \mathrm{~g} . \mathrm{Fe}_{2} \mathrm{O}_{3} ; \mathrm{Fe}=46.57 \%$

The mean value is $46.53 \% \mathrm{Fe}$.

A Common Error in the Gravimetric Determination of Iron.-From several private communications, as well as from our own experience, it appears that the results obtained from gravimetric determinations of iron are generally too high, and by an amount which may well be 2 per cent. of the total iron present. Nevertheless, there appear to be no specific references to this fact in the literature. The first two analyses of pyrite made by us gave identical results, 47.45 per cent. Fe, which are certainly much in excess of the true value. These analyses were performed exactly as described above, except that the iron was precipitated in beakers of Jena glass by means of ammonia, the purity of which had not been recently controlled. This was confirmed by a number of analyses of a solution of ferrous ammonium sulphate, in which the conditions of oxidation and precipitation were varied; the results, however, varied only from 0.004590 to $0.004623 \mathrm{~g}$. Fe per g. solution, as compared with $0.0045^{24}$ obtained volumetrically.

It was now found by evaporation in platinum that the ammonia left a residue; this ammonia had been redistilled not long before; nevertheless, from $25 \mathrm{cc}$. of it (about the amount used in a double precipitation), insoluble residues weighing $3.0-3.2 \mathrm{mg}$, were obtained. Now, since the usual weight of a precipitate of $\mathrm{Fe}_{2} \mathrm{O}_{3}$ is from $300-350 \mathrm{mg}$., it is evident that this source alone may be responsible for an error of as much as $\mathrm{r}$ per cent. of the total iron. The ammonia was therefore subjected to redistillation and the washed vapors absorbed by water in bottles of (I) ordinary glass, (2) Jena glass, and (3) ceresin (such as are used for hydrofluoric acid).

Direct tests made one month later showed the amount of residue from $25 \mathrm{cc}$. ammonia from each of these to be respectively: (I) $0.7 \mathrm{mg},{ }^{1}$ (2) $0.4 \mathrm{mg}$, (3) $0.0 \mathrm{mg}$. The ceresin bottle is thus entirely satisfactory $;^{2}$ the others have been attacked by the ammonia to a slight extent, but sufficient to produce an error in the determination of iron, which is not negligible.

That impurity in the ammonia is not responsible for the whole error is evident from the following analyses, in which the iron was precipitated twice in Jena glass beakers by means of pure ammonia: (a) $0.5048 \mathrm{~g}$. pyrite gave $0.3383 \mathrm{~g}$. ppt., whence $\mathrm{Fe}$ $=46.85$ per cent. (b) 0.5239 g. marcasite gave 0.3514 g. ppt., whence $\mathrm{Fe}=46.89$ per cent.

1 The distillation of this ammonia was conducted with very great care. The much larger amount of impurity given above is not to be referred to any special lack of care during the distillation, and that such an amoun is not exceptional is shown by the uniformly high results of a number of analyses in which other samples of ammonia weie used. However that may be, the figures represent real amounts, which may be encountered by any one who does not specially control the purity of the ammonia he uses.

2 Such bottles are used to some extent for this purpose. The magnitude of the errors caused by ammonia which has been kept in glass does not appear to have keen generally recognized.
Thus the error is still fully 0.6 per cent. of the total iron: Further, special experiments undertaken with the purpose of tracing down this source of error showed that the use of glass beakers was responsible, and that by discarding glass entirely, and by making the precipitations in platinum vessels, satisfactory results are obtained.

The definitive determinations of iron in pyrite and marcasite were made under these conditions, and as we have seen, correct results were obtained. It is evident that it is necessary to guard against these sources of error whenever ammonia is used as a precipitant; they may exert a specially large influence in the determination of aluminum, on account of its low atomic weight and of the fact that it is frequently determined by difference.

If it is necessary to determine both iron and sul phur in the same sample, the use of sodium carbonate for the precipitation of the iron is advisable on account of larger errors otherwise involved. Experience has shown that it is safer to add the sodium carbonate slowly, and in dilute solution (in order to diminish occlusion), and that it may sometimes be necessary to make more than one subsequent precipitation with ammonia, in order to obtain precipitates free from all foreign material.

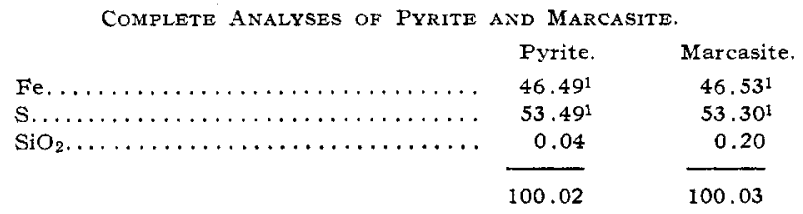

We have selected the gravimetric results for iron as nearer the truth; if the volumetric numbers are used, the summations become Ioo.25 for pyrite and Io0.05 for marcasite.

Comparison of Authors' Method with that of Hintz and Weber. - We have elsewhere shown that the method of Hintz and Weber, though a great improvement on those which preceded it, depends on a compensation of variable errors. The following figures (their best) give an idea of the accuracy. ${ }^{2}$

Assistant I.
48.25
48.62

Assistant II.
48.15
48.41

The variations in the work of each analyst are: I, 0.37 per cent., and II, 0.26 per cent., of the pyrite, or 0.7 per cent. and 0.5 per cent. of the total sulphur. Our own results show variations of 0.07 per cent. and 0.05 per cent. of the sulphide, $=0.13$ per cent. and o.ro per cent. of the total sulphur. These are the results obtained by using Carius' method in the oxidation; the results of the other methods, although they indicate a loss of sulphur, show equal uniformity in the determination of the sulphur present.

Application of the Method to Other Insoluble Sulphides.

1 Average of two determinations.

2 Z. anal. Chom., 45, 44 (1906). 
-Aithough we have not tried the method proposed in this paper in the analysis of other sulphides, the principles which we have discussed, viz., the error involved in the grinding of sulphides, the method of oxidation and the corrections for barium sulphate precipitates, would appear to be of perfectly general application. In the case of sulphides like those of antimony and bismuth in which not all the sulphur would be in soluble form after oxidation, an excess of sodium carbonate would be required to transform it all in to sodium sulphate, and the excess of sodium carbonate, of course, would have to be subsequently changed into sodium chloride, which, as we have seen, increases the errors due to occlusion and volatility. The method, however, is still applicable, though the errors would have to be determined for each special case.

\section{SUMMARY.}

It has been shown that when the sulphides of iron are ground for analysis, they suffer partial oxidation to sulphur dioxide and ferrous sulphate. If they are finely pulverized this error is not negligible; it may be reduced to 0.05 per cent. by gentle crushing to 20-mesh size, which is sufficiently fine for the proposed method of analysis. Inhomogeneous material, such as would be met with in commercial work, would have to be pulverized for the purpose of accurate sampling. In that case, the error could be determined by washing a weighed portion of the powder with boiled water in an atmosphere of carbon dioxide, and determining the iron in the washings; the operation is rather exacting on account of the readiness with which the moist sulphide oxidizes.

In the proposed method, the sample is oxidized in sealed tubes, according to Carius; this avoids all possible loss of sulphur. Lunge's and even Fresenius' method gave in our hands lower results, a fact which we attributed to a loss of sulphur during oxidation, occasioned by the use of coarse material, or perhaps, in Fresenius' method, to the presence of iron in the barium sulphate.

The iron is removed by two precipitations with sodium carbonate. The object of this is to avoid ammonium salts, which cause much larger losses of sulphur. In precipitating the barium sulphate several conditions must be carefully followed, viz., the free acid must be reduced to a small measured quantity, and the precipitation must be made at a measured rate. These two conditions are necessary because they determine the composition of the precipitate, which is not pure barium sulphate, while the first determines also the loss by solubility.

In every case, three corrections must be made on the weight of the barium sulphate precipitate: (I) a correction for solubility of the precipitate, which depends on the volume of the solution and the quantity of free acid it contains; (2) a correction for the occlusion of sodium sulphate by the precipitate, which depends on many conditions, but chiefly on the quantity of alkali chloride originally present in the solution; (3) a correction for a certain amount of free sulphuric acid lost on ignition. This is not due to any sort of decomposition of the barium sulphate, but to the presence in the precipitate of "free" sulphuric acid, probably in the form of sodium acid sulphate. The most important conditions affecting this error are the quantity of free acid and of sodium chloride in the solution, and the rate at which the precipitation is made; an increase of either acid or sodium chloride increases the error; a rapid rate of precipitation decreases it, but so far as our experiments have been carried, there is not in this case sufficient uniformity in the results to allow of satisfactory corrections. Constants may be used in making all these corrections if the conditions set down are carefully followed, but otherwise they must be determined by methods given in the body of this paper. These corrections have been fully worked out by studying the precipitation of pure sodium sulphate under various conditions. The analytical data on the sulphides appear the more certain since they have been controlled by complete analyses of material which gave both positive and negative evidence of nearly theoretical purity.

The sum of the errors in this method, apart from that involved in the grinding, should not be over 0.2 per cent. of the total sulphur. The extreme variation in our own analyses was less than 0.15 percent. and the agreement was equally good when other methods of oxidation were combined with our own scheme of precipitation and correction. Hintz and Weber's method for sulphur in pyrite is the best hitherto described; its essential features are oxidation according to Lunge, and a rapid precipitation of the barium sulphate. Their own best published results, however, vary from 0.5 per cent. to 0.7 per cent. of the total sulphur.

Incidentally, it was learned that the precipitation of iron by ammonia involves much larger errors than have generally been supposed, if, as is customary, the ammonia is kept in glass bottles and the precipitation is made in glass beakers. The same error would affect the precipitation of alumina and other similar oxides.

Geophysical Laboratory,

CaRnegie InstituTion OF Washington,

Washington, D. C., March 3, 1910.

[Contribution from New Mexico Agricultural Experiment Station.]

EXAMINATION OF CANDELILLA WAX.

By R. F. HARE AND A. P. BJerRegaArd. Received March 1, 1910.

Description of the Plant.- - The wax here reported upon is found coating the entire surface of a plant that grows wild in the semi-arid regions of northern Mexico and southern Texas. The plant is reported 